\title{
Modeling and Control Design of a Vienna Rectifier Based Electrolyzer
}

\author{
José Luis Monroy-Morales, Máximo Hernández-Ángeles \\ Programa de Graduados e Investigación en Ingeniería Eléctrica \\ Instituto Tecnológico de Morelia \\ Morelia, Michoacán México \\ Email: jlmonroy_m@itmorelia.edu.mx, \\ mhernand_it@yahoo.com.mx
}

\author{
David Campos-Gaona, Rafael Peña-Alzola, \\ Martin Ordonez, Walter Mérida \\ Department of Electrical and Computer Engineering \\ The University of British Columbia \\ 2332 Main Mall. Vancouver, BC Canada V6T 1Z41 \\ Email: davidcg@ieee.org, rafaelpa@ece.ubc.ca, \\ mordonez@ece.ubc.ca, walter.merida@ubc.ca
}

\begin{abstract}
Hydrogen production is an interesting alternative of storing energy. Electrolyzers produce hydrogen through water electrolysis; the resulting hydrogen is later used to generate electricity by using fuel cells, that reverse the process. Electrolyzers use rectifiers to convert the grid $a c$ voltage into $d c$ voltage for supplying the electrolyzer cells. Previous research used a rectification process based on conventional rectifiers (diode- or thyristor-based) which draw non-sinusoidal current from the main grid. This requires increased filtering to prevent power quality problems and equipment malfunctioning/failure. In addition, previous literature assumed simplified models for the power electronics converters and lacked a detailed control system. The Vienna rectifier is a non-regenerative converter that produces sinusoidal currents with low losses due to the reduced number of active switches. This manuscript proposes using the Vienna rectifier as an interface to connect electrolyzers to the $a c$ grid. The $d c$ voltage applied to the electrolyzer is regulated by using another dc-dc converter, which is selected to be a synchronous buck converter for simplicity and maximum efficiency. In this paper, the models of the Vienna rectifier, synchronous buck converter, and the electrolyzer are developed along with their respective controls. The control system has the ability to function in two operation modes for the overall reference: hydrogen production and power demand. The first one is adequate for grid-connected operation and the later for off-grid operation. Simulation results are given to show the validity of the proposed procedures.
\end{abstract}

Index Terms-Alkaline electrolyzer, vienna rectifier, hydrogen storage, fuel cell, hydrogen production, water electrolysis.

\section{INTRODUCTION}

The awareness in environmental pollution requires finding alternate ways to produce energy with low greenhouse gas emissions. There are various ways to store renewable energy. Battery banks can be a solution of energy storage, but they have medium energy density, self-discharge and leakage characteristics. They are also not suitable for long-term energy storage. Pumped hydro and compressed air energy storages are low cost options, but they have lower efficiencies and mostly dependent on the geographical location. Hydrogen is more suitable for long-term load leveling applications and fuel cells and electrolyzers can have a vital role in distributed energy generation and storage with minimal emissions [1,2]. Hydrogen is often referred to as the energy carrier of the future as it can be used to store intermittent renewable energy. Hydrogen can be produced from electrical power and water by using an electrolyzer. An electrolyzer is a device that converts electricity into chemical energy to produces hydrogen through the process of electrolysis [3-6]. Fuel cells can be used to return the energy to the grid or to an electric vehicle with no emissions, high efficiency and fast response. Fuel cells also have the capability to supply electricity for unlimited time as long as the required amount of hydrogen is present in the deposit.

An increase in energy demand and decrease in fossil fuels leads to the need to find alternate ways to produce energy with low greenhouse gas emissions. In consequence, there is a great need for accelerating the development and implementation of new technologies for alternative energies [7]. Electrolyzers use rectifiers to convert the grid $a c$ voltage into $d c$ voltage for supplying the electrolyzer cells. Previous research used a rectification process based on conventional rectifiers (diode- or thyristor-based) which draw nonsinusoidal current from the main grid. This requires increased filtering to prevent power quality problems and equipment malfunctioning/failure due to electromagnetic interference (EMI). In addition, previous literature assumed simplified models for the power electronics converters and lacked a detailed control system. The Vienna rectifier is one of the most popular topologies for three-phase power factor correction due to its good performance and relatively low costs [8-10]. The Vienna rectifier is a non-regenerative converter that produces sinusoidal currents with unity power factor and low losses due to the reduced number of active switches.

This manuscript proposes using the Vienna rectifier as an interface to connect electrolyzers to the $a c$ grid. Since the voltage applied to the electrolyzer is smaller than the $d c$-bus voltage, a $d c-d c$ buck converter is required between the $d c$ bus and the electrolyzer to regulate the power transmitted to the electrolyzer. A variation of the traditional buck power stage is the synchronous buck power stage. In this power stage, an active switch, such as power MOSFET, replaces the commutating diode and is selected so that its on-voltage drop is less than the forward drop of the rectifier, 


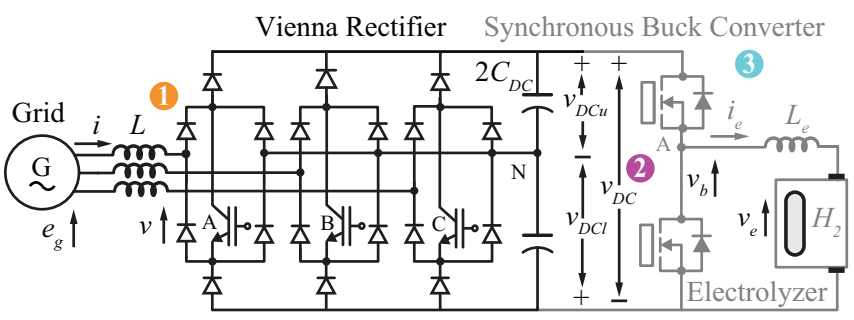

i (1) Grid-side Converter: Vienna Rectifier

I 2) Available DC-link for Auxiliary Services

I (3) Synchronous Buck Converter for Electrolyzer I

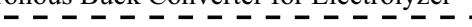

Fig. 1. Overall representation of the proposed system.

thus increasing efficiency [11]. In this paper, the models of the Vienna rectifier, synchronous buck converter, and the electrolyzer are developed along with their respective controls. The control system has the ability to function in two operation modes for the overall reference: hydrogen production and power demand. The first one is adequate for grid-connected operation and the later for off-grid operation. Fig. 1 shows the overall representation of the proposed new application. The Vienna rectifier has sinusoidal voltage and current in phase inputs and unity power factor and the synchronous buck converters control the amount of produced hydrogen/power. Simulation results are given to show the validity of the proposed procedures.

\section{Control of the Associated Power Electronics}

Rectifiers are needed in electrolyzer systems to transform the grid $a c$ voltage to $d c$ voltage. The output voltage of the fuel cell array varies significantly with the hydrogen supply rate and the pressure. Therefore, a $d c-d c$ converter is also required to control the electrolyzer system.

\section{A. Vienna Rectifier Control}

When using carrier-based pulse width modulation (PWM) and unity power factor the control of the Vienna rectifier is very similar to that of the full-bridge converter. The control employs a rotating reference frame synchronized with the $a c$ grid voltage vector by using a phase-locked loop $(P L L)$. The voltages and currents occur as constant vectors in the $d-q$ reference frame in steady state. Considering the converter system connected to grid, the phase voltages and currents are given by the equation,

$$
v_{a b c}=R i_{a b c}+L \frac{d i_{a b c}}{d t}+V_{a b c, c o n v}
$$

where $v_{a b c}, i_{a b c}, v_{a b c, c o n v}$ are $a c$ voltages, currents and converter input voltages respectively. $R$ and $L$ are the resistance and filter inductance between the converter and the $a c$ system. Assuming perfect synchronization with the grid voltage, the voltage equations in $d-q$ synchronous reference frame are:

$$
\begin{aligned}
& v_{d}=R i_{d}+L \frac{d i_{d}}{d t}-\omega_{g} L i_{q}+v_{d c o n v} \\
& v_{q}=R i_{q}+L \frac{d i_{q}}{d t}+\omega_{g} L i_{d}+v_{q c o n v}
\end{aligned}
$$

The subscript $d$ and $q$ stand for direct and quadrature respectively. In this configuration, the active and reactive power are controlled by the $i_{d}$ and $i_{q}$ currents respectively. The control system is based on nested loops with fast inner current control loops and slower outer $d c$ voltage control loop. The current reference for $i_{q}$ is set to zero for unity power factor.

Similarly on the output side,

$$
I_{d c}=C \frac{d V_{d c}}{d t}+I_{L}
$$

The power balance relationship between the $a c$ input and $d c$ output is given as,

$$
P=\frac{3}{2}\left(v_{d} i_{d}+v_{q} i_{q}\right)=V_{d c} I_{d c}
$$

where $V_{d c}$ and $I_{d c}$ are $d c$ output voltage and current respectively.

The grid voltage vector is defined to be along the $d$-axis direction, and then a virtual grid flux vector can be assumed to be acting along the $q-a x i s$. With this alignment, $v_{q}=0$ and the instantaneous real and reactive power injected into or absorbed from $a c$ system is given by,

$$
\begin{gathered}
p=\frac{3}{2} v_{d} i_{d} \\
q=-\frac{3}{2} v_{d} i_{q}
\end{gathered}
$$

Hence, the transformation into rotating $d-q$ coordinate system oriented with respect to the grid voltage vector, leads to a split of the mains current into two parts. One part determines the contribution which gives required power flow into the $d c$ bus while the other part defines the reactive power condition. The equations (6) and (7) show directly the possibility to control two current components independently. The overall scheme is shown in Fig. 2.

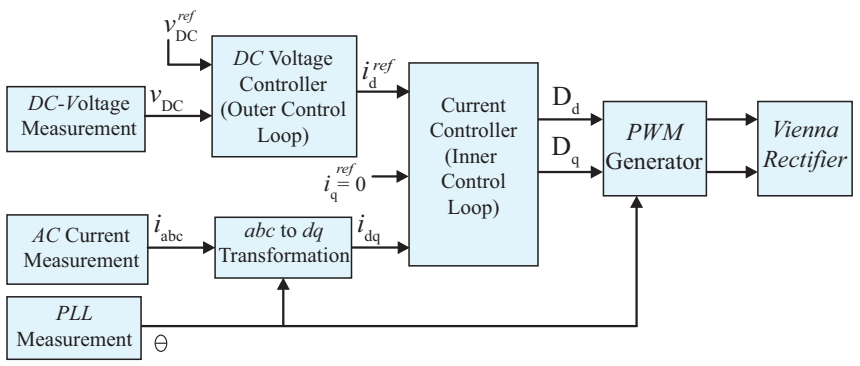

Fig. 2. Overall scheme of vectorial Vienna rectifier control.

The inner current control block is represented by the general block diagram shown in Figure 3.

The current control block use two $P I$ regulators, respectively for $d$ and $q$ axis current control. They transform the error between the comparison of $d$ and $q$ components of current into voltage value. Each block of the control system 


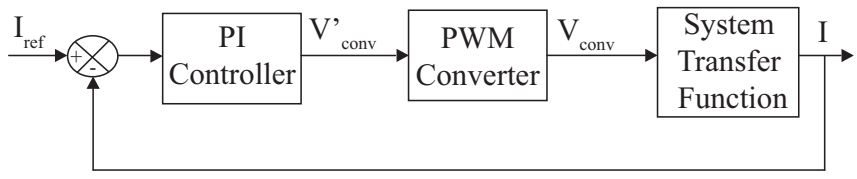

Fig. 3. General Block Diagram of Inner Current Control.

is discussed below.

The equation of the $P I$ regulator is:

$$
R(s)=K_{p}+\frac{K_{i}}{s}=K_{p}\left(\frac{1+T_{i} s}{T_{i} s}\right)
$$

thus for PI controller block,

$$
\left\{I_{\text {ref }}(s)-I(s)\right\}\left(K_{p}+\frac{K_{i}}{s}\right)=V_{\text {conv }}^{\prime}(s)
$$

the converter is considered as an ideal power transformer with a time delay. The output voltage of the converter is assumed to follow a voltage reference signal with an average time delay equals half of a switching cycle, due to converter switches. Hence, the general expression is:

$$
Y(s)=\frac{1}{1+T_{a} s}
$$

where $T_{a}=T_{\text {switch }} / 2$. Thus, for converter block,

$$
V_{\text {conv }}^{\prime}(s)\left(\frac{1}{1+T_{a} s}\right)=V_{\text {conv }}(s)
$$

The system behavior is governed by equations (2) and (3). As seen from the equations, the model of the converter in the synchronous reference frame is a multiple-input multiple output, strongly coupled nonlinear system. And it is difficult to realize the exact decoupled control with general linear control strategies. The transformed voltage equations of each axis have speed/frequency induced term, $w_{g} L i_{d}$ and $w_{g} L i_{q}$, that gives cross-coupling between the two axes. For each axis, the cross-coupling term can be considered as disturbance from control point of view. Thus, a dualclose-loop direct current controller with decoupled current compensation and voltage feed-forward compensation is required to obtain a good control performance. The equations (2) and (3) are rewritten as follows,

$$
\begin{aligned}
& V_{d}-V_{d c o n v}=L \frac{d i_{d}}{d t}+R i_{d}-w_{g} L i_{q} \\
& V_{q}-V_{q c o n v}=L \frac{d i_{q}}{d t}+R i_{q}-w_{g} L i_{d}
\end{aligned}
$$

Using separate inner loop current controllers for $i_{d}$ and $i_{q}$, give the output of voltage reference signals for two axes, which fed to the converter gives two references for the system, that are $d-q$ components of $V_{\text {conv }}(s): V_{d c o n v}$ and $V_{\text {qconv }}$. Using Equation (9) and Equation (11), these references are,

$$
V_{d c o n v}=\left(i_{\text {dref }}-i_{d}\right)\left(K_{p}+\frac{K_{i}}{s}\right) \frac{1}{1+s T_{a}}
$$

$$
V_{q c o n v}=\left(i_{q r e f}-i_{q}\right)\left(K_{p}+\frac{K_{i}}{s}\right) \frac{1}{1+s T_{a}}
$$

As seen from equations (12) and (13), the $d$ and $q$ components of the converter voltages are cross coupled. Hence, the reference used as input to system can be split in two components, one of which is obtained from converter whereas the other is a feed-forward term to eliminate the crosscoupling. With the compensation terms used for decoupling, the system input from converter is defined as

$$
\begin{aligned}
& V^{\prime} d c o n v=-\left(i_{d r e f}-i_{d}\right)\left(K_{p}+\frac{K_{i}}{s}\right)+w_{g} L i_{q}+V_{d} \\
& V^{\prime} q c o n v=-\left(i_{\text {qref }}-i_{q}\right)\left(K_{p}+\frac{K_{i}}{s}\right)-w_{g} L i_{d}+V_{q}
\end{aligned}
$$

Equations (16) and (17) when substituted in Eqn.(11) and equated to system equations (12) and (13) respectively, it gives,

$$
\begin{aligned}
& L \frac{d i_{d}}{d t}+R i_{d}=V_{d c o n v} \\
& L \frac{d i_{q}}{d t}+R i_{q}=V_{q c o n v}
\end{aligned}
$$

The cross coupling terms are thus cancelled out and independent control in $d$ and $q$ axis is achieved, which is one of the important features of vector control. Thus, current controllers of each axis operate independently. Figure 4 show the reduced diagram in $d$ and $q$ axes.

As seen from equations (18) and (19) the equations in $d$ and $q$ axis have a similar form. For this reason only the $d$-axis equations are used for further analysis. Consequently the other controller will also have the same parameters. By Laplace transformation the equation becomes:

$$
s i_{d}(s)=\left(-\frac{R}{L}\right) i_{d}(s)+\left(\frac{1}{L}\right) V_{d c o n v}(s)
$$

thus,

$$
i_{d}(s)=\left(\frac{1}{s L+R}\right) V_{d c o n v}(s)
$$

Hence the system transfer function is:

$$
G(s)=\left(\frac{1}{R}\right)\left(\frac{1}{1+s \tau}\right)
$$

Where the time constant of the line is defined as $\tau=L / R$.

The modulus optimum method is used to select the constants of the $P I$ inner controllers. This method provides a relatively fast and non-oscillatory closed-loop tracking response. The inner loop is designed to achieve fast 


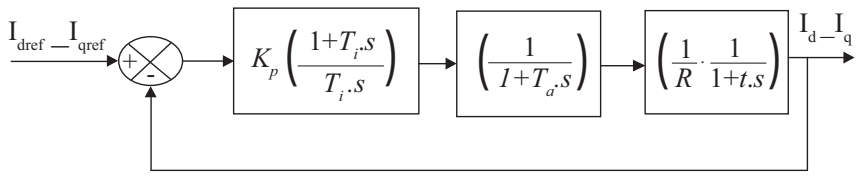

Fig. 4. Reduced block diagram in $d$ and $q$ axes.

response. From (22) it can be seen that the open-loop current system has a stable pole at $-R / L$. This pole can be cancelled with the zero provided by the $P I$ controller, where $K_{p}$ and $K_{i}$ are the proportional and integral constants of the $P I$ current controller. Thus, choosing $K_{i} / K_{p}=R / L$ and $K_{p} / L=1 / \tau$ where $\tau$ is the time constant of the closed-loop system. Hence the tuning of current controller by modulus optimum criteria can be summed up as,

$$
\begin{aligned}
K_{p} & =\frac{\tau R}{2 T a} \\
K_{i} & =R / \tau
\end{aligned}
$$

where $\tau=T_{i}$.

Dimensioning of the $d c$ link voltage controller is determined by the transfer function between the current reference value to be given and the $d c$ link voltage. The general diagram for the external controller is shown in Figure 5. The diagram consists of a $P I$ controller, the inner current controller and the power transfer function of the output element system.

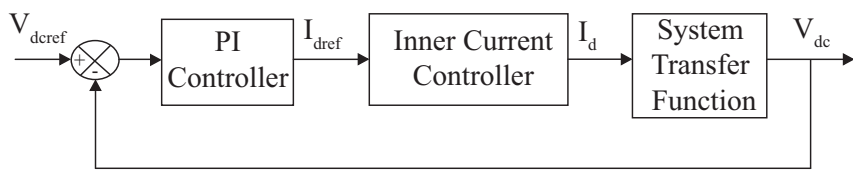

Fig. 5. General Block Diagram of Outer $d c$ Voltage Control.

The equation for $P I$ voltage controller is:

$$
R(s)=K_{p v}+\frac{K_{i v}}{s}=K_{p v}\left(\frac{1+T_{i v} s}{T_{i v} s}\right)
$$

where the subscript $v$ denotes the voltage regulator. The controller parameters $K_{p v}$ and $T_{i v}=K_{p v} / K_{i v}$ need to be designed for an optimum performance. For the PI controller block for outer voltage control,

$$
\left\{V_{d c r e f}(s)-V_{d c}(s)\right\}\left(K_{p v}+\frac{K_{i v}}{s}\right)=i_{d r e f}(s)
$$

The closed current loop gives the relation between $i_{d r e f}$ and $i_{d}$ in the block diagram as in Fig. 4. The second order transfer function of the inner current controller, can be approximated as:

$$
W(s)=\frac{1}{T_{e q} s+1}
$$

where $T_{e q}=2 T_{a}$.

From the equation (5), to obtain the transfer function of the converter, third block of Figure 5, and having the condition $V_{q}=0$, the relationship between $i_{d}$ and $I_{d c}$ is:

$$
I_{d c}=\left(\frac{3}{2}\right)\left(\frac{V_{d}}{V_{d c}}\right) i_{d}
$$

This defines the value of the current gain to be used from $d c$ current to input current or viceversa. Substituting this value in Eqn. (4), we get,

$$
C \frac{d V_{d c}}{d t}=\left(\frac{3}{2}\right)\left(\frac{V_{d}}{V_{d c}}\right)\left(i_{d}\right)-I_{L}
$$

It is possible to observe that the $d c$-link current equation is a nonlinear equation. For analyzing the stability of a non-linear system in the neighborhood of a steady state operating point, it is necessary to linearize the system model around the operating point and perform linear stability analysis. The reference point for linearization is found by specifying reference input, $V_{d c r e f}$ for the nonlinear model. Consequently the linear expression becomes,

$$
C \frac{d \Delta V_{d c}}{d t}=\left(\frac{3}{2}\right)\left(\frac{V_{d, 0}}{V_{d c, r e f}}\right) \Delta i_{d}
$$

By Laplace transformation it is:

$$
\frac{\Delta V_{d c}(s)}{\Delta i_{d}(s)}=\left(\frac{3}{2}\right)\left(\frac{V_{d, 0}}{V_{d c, r e f}}\right)\left(\frac{1}{s C}\right)
$$

The $d c$ link voltage controller controls the capacitor current so as to maintain the power balance. Hence under balanced conditions, $I c=0$. That is, $I_{d c}=I_{L}$.

Thus, the reference value of $i_{d}$ should be,

$$
i_{d}=\left(\frac{2}{3}\right)\left(\frac{V_{d c}}{V_{d}}\right) I_{d c}
$$

which is the feed-forward term, ensuring exact compensation for load variation. The overall control block diagram of the dc voltage controller based on Eqn. (26)-(33) is as shown in Fig. 6.

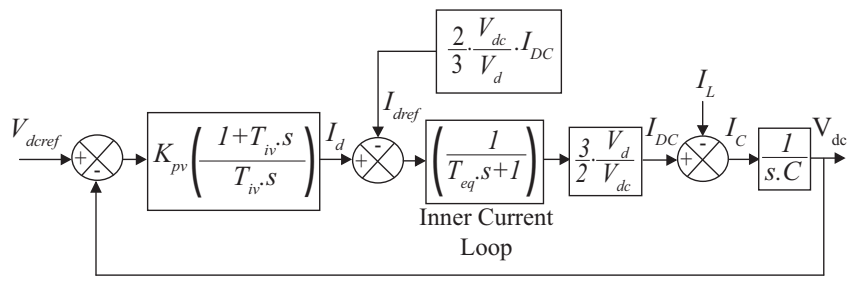

Fig. 6. Closed loop control diagram of $d c$ voltage controller. 
In cascade control, generally the inner loop is tuned according to modulus optimum condition because of fast response and simplicity whereas the outer loop according to symmetrical optimum condition for optimizing system behavior with respect to disturbance signals. From the system block diagram as developed in Fig.6, the open loop transfer function of the system without considering the feed-forward and the disturbance input is given by,

$$
G_{V, O L}(s)=K_{p v}\left(\frac{1+T_{i v} s}{T_{i v} s}\right) \frac{1}{T_{e q} s+1}\left(\frac{V_{d} w_{b} C}{V_{d c} s}\right)
$$

The open loop transfer function consists of double pole at origin. The system cannot be designed by cancelling the pole and zero, because it will result in two poles at origin and the system becomes unstable. Hence the design is chosen by using symmetrical optimum design criteria. Symmetrical Optimum method obtains a controller that forces the frequency response from a reference point to output as close as possible to that for low frequencies. The method has the advantage of maximizing the phase margin. As phase margin is maximized for given frequency, the system can withstand more delay, which is important for systems having delays. This method optimizes the control system behaviour with respect to disturbance input [12].

Eqn. (34) can be simplified by introducing $K=V_{d} / V_{d c}$, and $T_{c}=1 / w_{b} . C$ as follows,

$$
G_{V, O L}(s)=K_{p v}\left(\frac{1+T_{i v} s}{T_{i v} s}\right)\left(\frac{K}{T_{e q} s+1}\right)\left(\frac{1}{T_{c} s}\right)
$$

where $w_{b}=2 \pi f$, is the base frequency.

According to the tuning criteria derived, the parameters for tuning the outer controller by symmetrical optimum are,

$$
\begin{aligned}
T_{i v} & =a^{2} T_{e q} \\
K_{p v} & =\frac{T_{c}}{a K T_{e q}}
\end{aligned}
$$

where $T_{e q}=2 T_{a}$ and $T_{a}=\frac{T_{\text {switch }}}{2}=\frac{1}{2 f_{\text {switch }}}$.

The inner control time response is selected in $1 \mathrm{~ms}$, hence, the outer control is selected 10 times this value in order to get a good performance of the controller.

\section{B. Synchronous Buck Converter Control}

In the synchronous buck converters, the lower diode is replaced by a power MOSFET with lower on-voltage drop than the forward drop of the rectifier, thus increasing efficiency. The output voltage of the synchronous buck converter $V_{b}$ is set by the duty cycle $D$ :

$$
V_{b}=(D)\left(V_{d c}\right)
$$

with $V_{d c}$ the overall $d c$-link voltage assumed for constant for control. A simple analysis of buck converter circuit shown in Fig. 1 results in the following equation:

$$
(D)\left(V_{d c}\right)-V_{e}=L_{e} \frac{d i_{e}}{d t}+R_{e} i_{e}
$$

where $i_{e}$ and $V_{e}$ is the electrolyzer current and voltage respectively. $L_{e}$ is an connection inductor to the electrolyzer and $R_{e}$ is parasitic resistance. Applying Laplace transform to (39) and rearranging, it follows:

$$
\frac{i_{e}(s)}{(D s) V_{d c}}=\frac{1}{L_{e} s+R_{e}}
$$

Using the transfer function from equation (40) the buck converter current is controlled in a closed loop as shown in Fig. 7. Assuming the overall $d c$-link voltage is constant, the consumed power is proportional to the electrolyzer current $i_{e}$. Additionally, it is shown in the next section that the hydrogen productions is also proportional to the electrolyzer current.

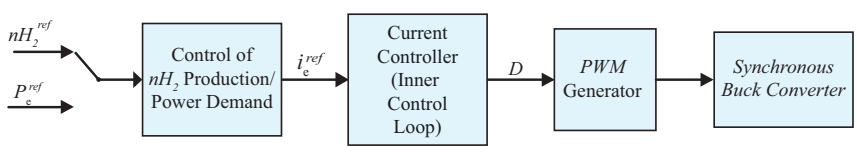

Fig. 7. Scheme control of synchronous buck converter output current.

\section{Electrochemical Model of Electrolyzers}

The most economically appropriate for an energy storage system are the alkaline water electrolyzers. The decomposition of water into hydrogen and oxygen can be achieved by passing a $d c$ electricity current between two electrodes separated by a aqueous potassium hydroxide $(\mathrm{KOH})$ electrolyte with good ionic conductivity [13].

I-U Characteristic Curve: The kinetic properties around the electrodes in an electrolyzer cell can be modeled based on empirical data of different proposed $I-V$ curves. A representative plot of the theoretical and actual voltages for an alkaline water electrolyzer versus the current density at high and low operating temperatures is shown in Fig. 8. The basic relationship between current and cell voltage in a given temperature is:

$$
V=V_{\text {rev }}+\frac{I}{A} r+s \log \left(\frac{I}{A} t+1\right)
$$

where $I$ is the current required for the electrolysis, $A$ is the area of electrodes, $r$ is the parameter related to ohmic resistance of the electrolyte, $s$ and $t$ are the over voltage 


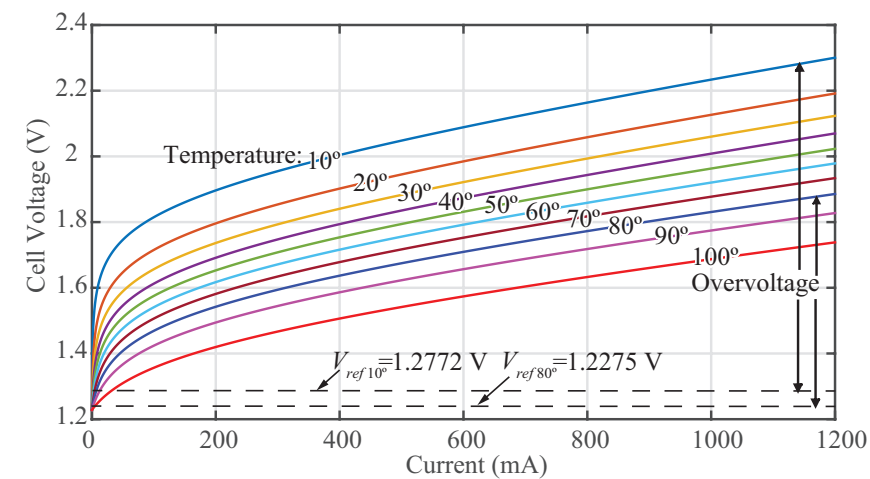

Fig. 8. Typical I-V curves for an electrolyzer cell at high and low temperatures.

coefficients on electrodes and $V_{\text {rev }}$ is the reversible voltage. The thermodynamics of the electrochemical reactions is an important factor to be taken into account. The changes in enthalpy and entropy of the water splitting reaction induce changes in Gibb's energy and consequently in the $V_{\text {rev }}$. These parameters are directly affected by the working conditions of the Alkaline Electrolyzer. The reversible voltage can be expressed as:

$$
V_{\text {rev }}=\frac{\Delta G}{z F}
$$

where $\Delta G$ is Gibb's energy, $z$ is the number of electrons transferred in each reaction, here it is 2 , and $F$ is the Faraday constant. In standard condition, $25^{\circ} \mathrm{C}$ and 1 bar, the change of Gibb's energy of water splitting is $\Delta G^{\circ}=237 \mathrm{~kJ} / \mathrm{mol}$. In order to relate the ohmic resistance parameter $r$ and over voltage coefficient $t$, the equation (41) can be modified in more detailed way as:

$$
\begin{array}{r}
V=V_{\text {rev }}+\frac{I}{A}\left(r_{1}+r_{2} T\right) \\
+s \log \left[\frac{I}{A}\left(t_{1}+\frac{t_{2}}{T}+\frac{t_{3}}{T^{2}}+1\right)\right]
\end{array}
$$

where $T$ is the electrolyte temperature.

Hydrogen Production: Faraday efficiency is the proportion of the actual and theoretical hydrogen production in the electrolyzer [14]. One of the parameters that control the hydrogen production is current, so another name of Faraday efficiency is current efficiency. It can be noted that parasitic current increases with the decrement of current density and the increment of temperature resulting the reduction of Faraday efficiency. This phenomenon can be expressed as:

$$
n_{F}=\frac{\left(\frac{I}{A}\right)^{2}}{f_{1}+\left(\frac{I}{A}\right)^{2}} * f_{2}
$$

where $f 1$ and $f 2$ are the parameters related to Faraday efficiency.

Normally a number of electrolyzer cells are connected in series in a stack and some stacks are connected in parallel. The number of such electrolyzer cells has an impact on the total hydrogen production [15]. The production rate is

$$
n_{H^{2}}=n_{F} \frac{n_{c} I}{z F}
$$

where $n_{c}$ is the number of electrolyzer cells per stack.

The total amount of energy needed in water electrolysis is equivalent to the change in enthalpy $\Delta H$. The standard enthalpy for splitting water is $\Delta H^{\circ}=286 \mathrm{~kJ} \mathrm{~mol}^{-1}$. The total energy demand $\Delta H$ is related to the thermoneutral cell voltage by the expression

$$
V_{t n}=\frac{\Delta H}{z F}
$$

The energy efficiency can be calculated from the thermo neutral voltage and the cell voltage by the expression

$$
n_{e}=\frac{V_{t n}}{V}
$$

The electrical inefficiencies result the unwanted heat generation in the electrolyzer which has an indirect influence on Faraday efficiency.

\section{Simulation Results}

Simulations were conducted in order to verify the performance of the system shown in Fig. 1 along with its control strategy. The hydrogen production operative mode is used when a fixed amount of hydrogen is required, up to the maximum attainable limit of hydrogen production. This operation mode is adequate when the system is connected to the main grid. Fig. 9 shows the current and voltage waveform of phase $\boldsymbol{a}$ in $p u$ when a step change from 0.5 to $0.8 \mathrm{pu}$ in the hydrogen production reference signal is applied (hydrogen production mode).

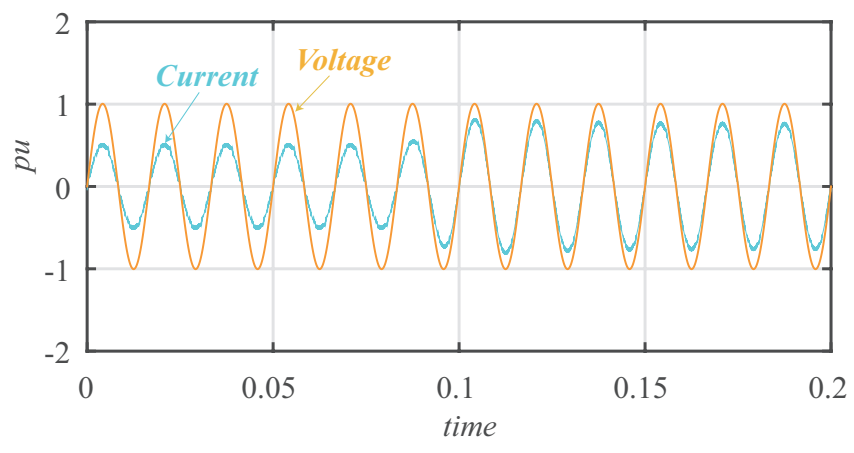

Fig. 9. Hydrogen production operating mode, voltage and current of phase $\boldsymbol{a}$ in $p u$ with a change from 0.5 to 0.8 in the reference signal.

The power demand operating mode is selected when the system has an excess of power production which can be stored as hydrogen. This operation mode is adequate for 
demand side management or off-grid configuration. Fig. 10 shows the current and voltage waveform of phase $\boldsymbol{a}$ in $p u$ when a step change from 0.5 to $0.8 \mathrm{pu}$ in the power demand reference signal is applied (power demand mode).

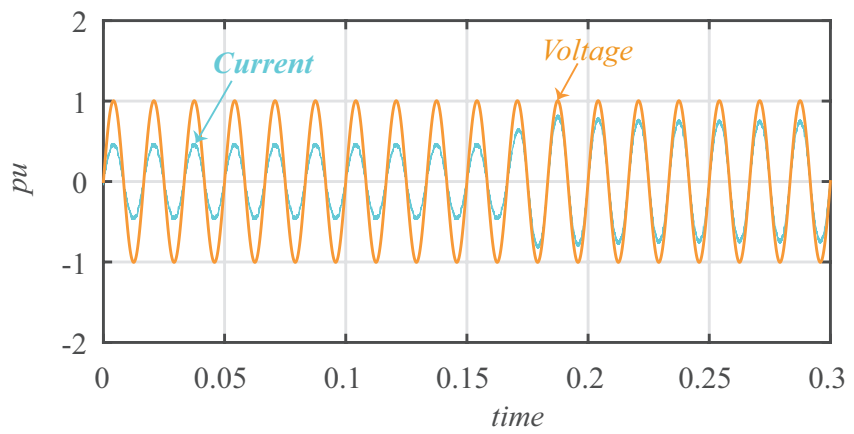

Fig. 10. Power demand operating mode, voltage and current of phase $\boldsymbol{a}$ in $p u$ with a change from 0.5 to 0.8 in the reference signal.

In both cases, Figs. 9 and 10, the current waveform changes accordingly while remaining in phase with the $a c$ voltage (unity power factor).

Fig. 11 shows the performance of the hydrogen production operative mode when the hydrogen production reference signal is changed from 0.5 to $0.8 \mathrm{pu}$. As seen Fig. 11 the controller tracks hydrogen production reference signal in a fast and stable manner. Fig. 12 shows the performance of the power reference operative mode when the excess of power production in the $a c$ grid changes from 0.5 to $0.8 \mathrm{pu}$. As seen in Fig. 12 the controller drives the Vienna rectifier to absorb 0.8 of power in a fast and stable manner.

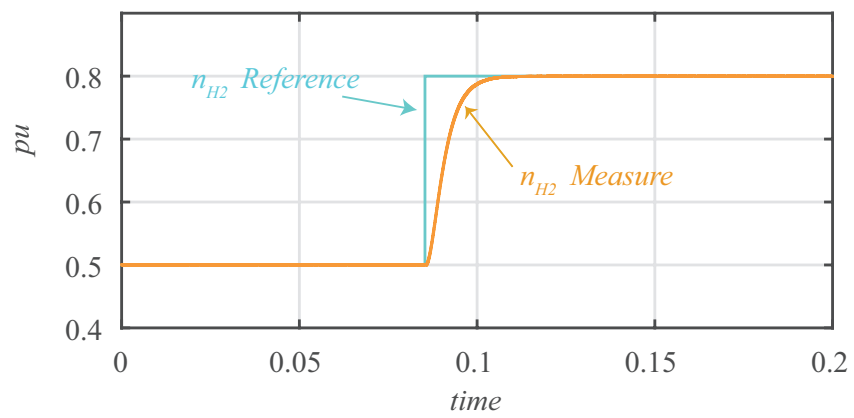

Fig. 11. Hydrogen production operating mode, changes in the reference signal.

Figs. 13 and 14 show the change of current in the synchronous buck converter when a reference change is applied in hydrogen production mode and power reference mode respectively. The slower response of the hydrogen production mode is because of the larger time constant of the electrochemical process. This simulation results corroborate the proper functioning of the Vienna rectifier and the electrolyzer control modes.

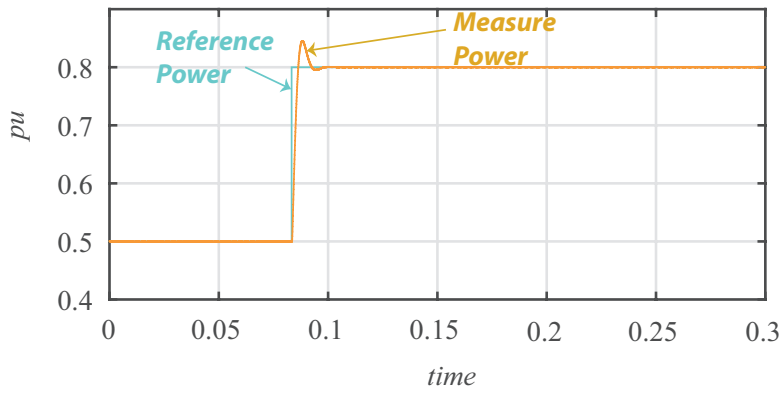

Fig. 12. Power demand operating mode, changes in the reference signal.

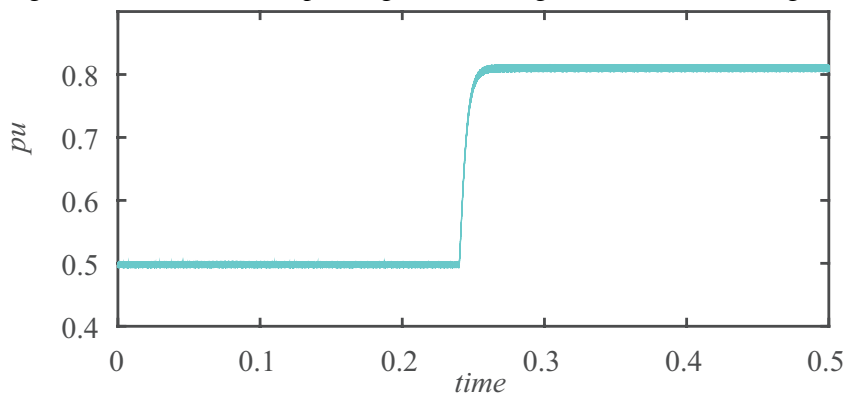

Fig. 13. Hydrogen production operating mode, change in the Synchronous Buck converter current.

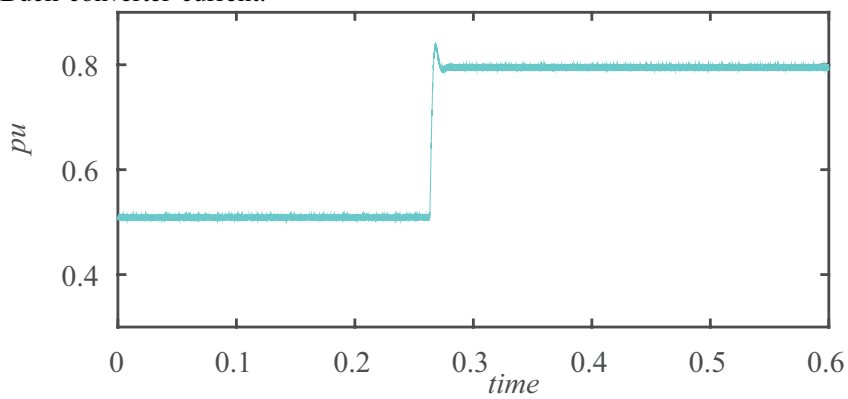

Fig. 14. Power demand operating mode, change in the Synchronous Buck converter current.

\section{CONCLUSION}

The complete model of the Vienna rectifier, the synchronous buck and the electrical to hydrogen production process was developed along with the different controls. The whole system is able to characterize the relation among the different physical quantities to determine the control action that ensures the proper operation of the electrolyzer. Additionally, the electricity-to-hydrogen conversion process is carried out efficiently (because of the Vienna rectifier topology), with sinusoidal current and unity power factor in the AC mains. The proposed system operates in two modes; hydrogen production and power demand operating mode. The ability to select between these two operative modes is highly beneficial for electrical grids connected to intermittent power sources and/or requiring capability for demand side management. Simulation results corroborate the proper functioning of the proposed new application using the Vienna rectifier for the electrolyzer system.

\section{REFERENCES}

[1] C. Nicy and R. Punitharaji, "Isolated wind-hydro hybrid system using permanent magnet synchronous generator and battery storage with 
fuzzy logic controller," in Green Computing Communication and Electrical Engineering (ICGCCEE), 2014 International Conference on, March 2014, pp. 1-6.

[2] M. Kolhe and O. Atlam, "Empirical electrical modeling for a proton exchange membrane electrolyzer," in Applied Superconductivity and Electromagnetic Devices (ASEMD), 2011 International Conference on, Dec 2011, pp. 131-134.

[3] R. Takahashi, H. Kinoshita, T. Murata, J. Tamura, M. Sugimasa, A. Komura, M. Futami, M. Ichinose, and K. Ide, "Output power smoothing and hydrogen production by using variable speed wind generators," Industrial Electronics, IEEE Transactions on, vol. 57, no. 2, pp. 485-493, Feb 2010.

[4] O. Bendakha and S. Larbi, "Hydrogen production system analysis using direct photo-electrolysis process in algeria," in Renewable Energy Research and Applications (ICRERA), 2013 International Conference on, Oct 2013, pp. 1123-1128.

[5] I. S.J. Anand and V. Bale, "Exergetic assessment of solar hydrogen production methods,", Int. J. Hydrogen Energy. vol.35, pp.4901-8, 2010.

[6] W. S.-Y. X. Lan and L. You-Rong, "Advances in solar hydrogen production via two-step water-splitting thermochemical cycles based on metal redox reactions," Renew Energ, vol. 41, pp. 1-12, 2012.

[7] H. Teymour, D. Sutanto, K. Muttaqi, and P. Ciufo, "Solar pv and battery storage integration using a new configuration of a three-level npc inverter with advanced control strategy," Energy Conversion, IEEE Transactions on, vol. 29, no. 2, pp. 354-365, June 2014.

[8] X. Jiang, J. Yang, J. Han, and T. Tang, "A survey of cascaded multi-level pwm rectifier with vienna modules for hvdc system," in Electronics and Application Conference and Exposition (PEAC), 2014 International, Nov 2014, pp. 72-77.

[9] C. Qiao and K. M. Smedley, "Three-phase unity-power-factor vienna rectifier with unified constant-frequency integration control," in Power Electronics Congress, 2000. CIEP 2000. VII IEEE International, 2000 pp. $125-130$.

[10] S. H. J. Bhumika S., "Three phase vienna rectifier for wind power generation system," International Journal of Research in Engineering and Technology, eISSN: 2319-1163 - pISSN: 2321-7308, Volume: 03 Special Issue: 03 - May-2014 — NCRIET-2014.

[11] C. Wilson, J. Hung, and R. Dean, "A sliding mode controller for twophase synchronous buck converters," in IECON 2012 - 38th Annual Conference on IEEE Industrial Electronics Society, Oct 2012, pp. 2150-2155.

[12] J. A. S. T. M. U. Chandra Bajracharya, Marta Molinas, "Understanding of tuning techniques of converter controllers for vsc-hvdc," NORPIE/2008, Nordic Workshop on Power and Industrial Electronics, June 9-11, 2008.

[13] O. Ulleberg, "Modeling of advanced alkaline electrolyzers: a system simulation approach," International Journal of Hydrogen Energy, pp. 21-33, 28, (2003).

[14] M. M. ul Karim and M. T. Iqbal, "Dynamic modeling and simulation of alkaline type electrolyzers," in Electrical and Computer Engineering, 2009. CCECE '09. Canadian Conference on, May 2009, pp. 711715 .

[15] I. D. d. C. Mendaza, "An interactive energy system with grid, heating and transportation systems," Ph.D. dissertation, Aalborg University, Department of Energy Technology, Denmark., August 2014. 